\title{
Engineered human mesenchymal stem cells for neuroblastoma therapeutics
}

\author{
VALENTINA NIEDDU ${ }^{1}$, ROBERTA PIREDDA ${ }^{1}$, DANIEL BEXELL ${ }^{2}$, JACK BARTON $^{3}$, JOHN ANDERSON $^{3}$, \\ NEIL SEBIRE $^{4}$, KRISHNA KOLLURI ${ }^{5}$, SAM M. JANES $^{5}$, EMMANOUIL KARTERIS $^{1}$ and ARTURO SALA ${ }^{1}$ \\ ${ }^{1}$ Department of Life Sciences, Research Institute of Environment, Health and Societies, Brunel University London, \\ Uxbridge, Middlesex UB8 3PH, UK; ${ }^{2}$ Department of Laboratory Medicine, Translational Cancer Research, \\ Lund University, SE-221 00 Lund, Sweden; ${ }^{3}$ Institute of Child Health, Unit of Molecular Haematology and \\ Cancer Biology, University College London, London WC1N 1EH; ${ }^{4}$ Developmental Biology and Cancer Programme, \\ UCL Great Ormond Street Institute of Child Health, University College London, London WC1N 1EH; \\ ${ }^{5}$ Lungs for Living Research Centre, UCL Respiratory, University College London, London WC1E 6JF, UK
}

Received October 16, 2018; Accepted February 21, 2019

DOI: 10.3892/or.2019.7152

\begin{abstract}
Drug-resistant neuroblastoma remains a major challenge in paediatric oncology and novel and less toxic therapeutic approaches are urgently needed to improve survival and reduce the side effects of traditional therapeutic interventions. Mesenchymal stem cells (MSCs) are an attractive candidate for cell and gene therapy since they are recruited by and able to infiltrate tumours. This feature has been exploited by creating genetically modified MSCs that are able to combat cancer by delivering therapeutic molecules. Whether neuroblastomas attract systemically delivered MSCs is still controversial. We investigated whether MSCs engineered to express tumour necrosis factor-related apoptosis-inducing ligand (TRAIL) could: i) cause death of classic and primary neuroblastoma cell lines in vitro; ii) migrate to tumour sites in vivo; and iii) reduce neuroblastoma growth in xenotransplantation experiments. We observed that classic and primary neuroblastoma cell lines expressing death receptors could be killed by TRAIL-loaded MSCs in vitro. When injected in the peritoneum of neuroblastoma-bearing mice, TRAIL-MSCs migrated to tumour sites, but were unable to change the course of cancer development. These results indicated that MSCs have the potential to be used to deliver drugs in neuroblastoma patients, but more effective biopharmaceuticals should be used instead of TRAIL.
\end{abstract}

Correspondence to: Professor Arturo Sala or Dr Emmanouil Karteris, Department of Life Sciences, Research Institute of Environment, Health and Societies, Brunel University London, Heinz Wolff Building, Kingston Lane, Uxbridge, Middlesex UB8 3PH, UK

E-mail: arturo.sala@brunel.ac.uk

E-mail: emmanouil.karteris@brunel.ac.uk

Key words: mesenchymal stem cells, neuroblastoma, death receptors

\section{Introduction}

Neuroblastoma, one of the most aggressive extracranial solid tumours occurring in childhood, remains a major cause of cancer-related deaths in infancy (1). Despite therapeutic strategies based on chemotherapy, radiotherapy, surgery, GD2-targeted immunotherapy, stem cell transplant and treatment with 13-cis-retinoic acid, high-risk neuroblastoma outcome remains poor, with a 5-year event-free survival $<40 \%$ (2-5). Tumours show initial response to therapeutic interventions but typically relapse into an incurable form of the disease. Moreover, several drugs cause severe side effects, including cognitive impairment and retarded growth (6). Thus, to reduce drug toxicity and to improve the outcome and the lifestyle of the patients affected by neuroblastoma, additional therapeutic options are required.

Recently, cell-based approaches have been increasingly investigated for the delivery of therapeutics agents. Mesenchymal stem cells are multipotent adult stem cells isolated from the umbilical cord, bone marrow and fat tissue and can differentiate into multiple tissues including bone, cartilage, muscle, fat cells and connective tissue (7-12). Bone marrow-derived mesenchymal stem cells (MSCs) are ideally suited for the delivery of anticancer agents to tumours, including cytokines, interferons and prodrugs (13-15).

MSCs are particularly suitable for the role of vectors for anticancer therapies for various reasons (16). MSCs are immunologically inert due to their low expression of constitutive major histocompatibility complex 1 (MHC1) and lack of MHC2 and co-stimulatory molecules CD80, CD86 and CD40, meaning that allogeneic cells can be used in immunocompetent patients abrogating the need of immunosuppressive therapies (17). Furthermore, MSCs are able to migrate to and incorporate into the tumour stroma when administered in vivo and, if engineered with viral vectors, can deliver therapeutic molecules that inhibit tumours or metastatic growth $(18,19)$.

In recent studies, MSCs have been engineered to express IFN- $\gamma$, IL-12, IL-24 and tumour necrosis factor-related 
apoptosis inducing ligand (TRAIL), to induce death of tumour cells $(15,20)$.

TRAIL is a member of the TNF superfamily and interacts with fully functional death receptors DR4 and DR5, decoy receptors DCR1 and DCR2, and osteoprotegerin (OPG), which lack functional cytoplasmic signalling domains (21-23). TRAIL is an interesting anticancer molecule, since it causes apoptosis of cancer cells bearing DR4 and DR5 death receptors, but it is unable to harm normal cells which express high levels of TRAIL decoy receptors and low levels of TRAIL death receptors on their surface. TRAIL-mediated killing is not dependent on a specific molecular alteration and all molecular subtypes or high-risk tumours are potentially amenable to TRAIL killing. Thus, from a clinical point of view, TRAILbased therapies are especially attractive due to the extremely high therapeutic index.

Clinical trials in which cancer patients have been treated with soluble, truncated forms of TRAIL have been unsuccessful, due to the extremely short half-life of the molecule in the blood stream and the emergence of resistance; therefore, efficient TRAIL delivery is essential $(24,25)$. The major advantage of using MSCs to deliver TRAIL is that it is continuously produced at the tumour site, overcoming the problem of the short half-life of the protein. Furthermore, it has been revealed that the full-length TRAIL protein secreted by MSCs transduced with a lentiviral vector containing the TRAIL cDNA, can resolve resistance in lung, colorectal and breast cancer (26-28). These cells are also able to clear lung metastasis in mice injected with extremely aggressive breast cancer cells or reduce the growth of mesothelioma cells in mouse models (29).

Notably, a protease inhibitor currently used in the clinic, Bortezomib, is able to enhance TRAIL-mediated killing of neuroblastoma cells or render them sensitive to the molecule, suggesting that in a TRAIL therapy setting, the problem of resistance could be managed pharmacologically (30-32).

In the present study, we investigated the tumour-homing ability and anticancer activity of TRAIL-MSCs in the context of neuroblastoma.

\section{Materials and methods}

Cell lines. The primary human neuroblastoma cell lines A5, 2820, 0396 and 1043008 were isolated at the Institute of Child Health (University College London, London, UK) by disaggregating surgical resections. The patient characteristics are summarised in Table I. Consent for the isolation of cell lines from patient material was obtained in accordance with the Great Ormond Street Hospital (London, UK) Ethics Committee regulations.

The patient-derived xenograft (PDX) cells LU-NB-1, LU-NB-2 and LU-NB-3 were established and characterized at the laboratory of Dr Daniel Bexell (Lund University, Lund, Sweden) as previously described (33). hNB cells were isolated from a tumour metastasised in the neck of a 3-year-old male patient in 2011 (34). MSC-TRAIL was generated at the laboratory of Dr Samuel Janes (University College London, London, UK) as previously described (26).

SKNAS, IMR-32, Kelly, SHEP, LA-N-5 and SH-SY5Y were obtained from the American Type Culture Collection
(ATCC; Teddington, Middlesex, UK). LA-N-1 and patient-derived neuroblastoma cell lines were provided by Dr John Anderson (Institute of Child Health). LA-N-1, SKNAS, SHEP and SH-SY5Y were grown in Dulbecco's modified Eagle's medium (DMEM) (Gibco; Thermo Fisher Scientific, Inc., Waltham, MA, USA) supplemented with $10 \%$ fetal bovine serum (FBS) (Gibco; Thermo Fisher Scientific, Inc.), $1 \%$ penicillin/streptomycin (Gibco; Thermo Fisher Scientific, Inc.), $2 \mathrm{mM}$ glutamine (Gibco; Thermo Fisher Scientific, Inc.) and $10 \mathrm{mM}$ sodium pyruvate (Gibco; Thermo Fisher Scientific, Inc.). IMR-32, Kelly, LA-N-5 were cultured in RPMI-1640 medium (Gibco; Thermo Fisher Scientific, Inc.) containing $10 \%$ FBS, 2 mM glutamine supplemented, $10 \mathrm{mM}$ sodium pyruvate and $10 \mathrm{mM}$ non-essential amino acids (NEAA) (Gibco; Thermo Fisher Scientific, Inc.). hNB cells were cultured in RPMI-1640 medium supplemented with $20 \%$ fetal calf serum (FCS) (Gibco; Thermo Fisher Scientific, Inc.), $2 \mathrm{mM}$ glutamine, $10 \mu \mathrm{M}$ 2-mercaptoethanol (Thermo Fisher Scientific, Inc.), $1 \mathrm{mM}$ sodium pyruvate, $1 \%$ penicillin/streptomycin and $10 \mathrm{mM}$ NEAA. TRAIL-MSCs were grown in $\alpha$-MEM (Gibco; Thermo Fisher Scientific, Inc.) with $16 \% \mathrm{FBS}, 4 \mathrm{mM} \mathrm{L}$-glutamine and $1 \%$ penicillin/ streptomycin.

Primary cell lines were grown in stem cell medium (DMEM/F-12 medium with glutamine, $1 \%$ penicillin/streptomycin, 2\% B27 supplement (Thermo Fisher Scientific, Inc.), $40 \mathrm{ng} / \mathrm{ml}$ of basic fibroblast growth factor (FGF) (PeproTech, Inc., Rocky Hill, NJ, USA) and $20 \mathrm{ng} / \mathrm{ml}$ of epidermal growth factor (EGF) (PeproTech, Inc.). All cell lines were incubated at $37^{\circ} \mathrm{C}$ and $5 \% \mathrm{CO}_{2}$.

Western blotting. Cells were lysed in Laemmli buffer (cat. no. NP0007; Thermo Fisher Scientific, Inc.) supplemented with $\beta$-mercaptoethanol (cat. no. 21985023; Thermo Fisher Scientific, Inc.) and protein concentrations were determined using a Pierce BCA Protein Assay kit (cat. no. 23227; Thermo Fisher Scientific, Inc.). The protein extracts $(20 \mu \mathrm{g})$ were resolved in 10\% acrylamide gel and transferred onto nitrocellulose membranes which were blocked in 5\% non-fat dry milk for $1 \mathrm{~h}$ at room temperature. The membranes were incubated overnight at $4^{\circ} \mathrm{C}$ with the primary antibodies followed by incubation with the goat-anti rabbit IgG HRP-conjugated secondary antibody (dilution 1:3,000; cat. no. 1706515; Bio-Rad Laboratories, Inc., Hercules, CA, USA) for $1 \mathrm{~h}$ at room temperature. Membranes were exposed to ECL Western Blotting substrate (cat. no. 32106; Thermo Fisher Scientific, Inc.) as described in the manufacturer's protocol.

The following antibodies were used: DR4 (dilution 1:1,000; cat. no. 42533), DR5 (dilution 1:1,000; cat. no. 8074), $\alpha$-tubulin (dilution 1:1,000; cat. no. 2144; all were from Cell Signalling Technology, Danvers, MA, USA).

In vitro co-culture and cell death assay. A total of 10,000 Dil-labeled (cat. no. V22885; Thermo Fisher Scientific, Inc.) neuroblastoma cells were plated in 96-well plates, to which control medium, $50 \mathrm{ng} / \mathrm{ml} \mathrm{r-TRAIL} \mathrm{(cat.} \mathrm{no.} \mathrm{310-04;}$ PeproTech, Inc.), $20 \mathrm{nM}$ Bortezomib (cat. no. S-1013; Selleck Chemicals, Houston, TX, USA), 10,000 TRAIL-MSCs or their combinations were added after $24 \mathrm{~h}$. Floating and adherent cells were harvested after $48 \mathrm{~h}$ after plating. Apoptosis was 
Table I. Primary cell lines and patient information (Great Ormond Street Hospital cohort).

\begin{tabular}{|c|c|c|c|c|}
\hline $\begin{array}{l}\text { Pathology } \\
\text { number }\end{array}$ & A5 & 2820 & 1043008 & 0396 \\
\hline Procedure & Diagnostic biopsy & Diagnostic biopsy & Biopsy, second relapse & Diagnostic biopsy \\
\hline Diagnosis & $\begin{array}{l}\text { Poorly differentiated } \\
\text { neuroblastoma }\end{array}$ & $\begin{array}{l}\text { Poorly differentiated } \\
\text { neuroblastoma }\end{array}$ & $\begin{array}{l}\text { Poorly differentiated } \\
\text { neuroblastoma }\end{array}$ & $\begin{array}{l}\text { Poorly differentiated } \\
\text { neuroblastoma }\end{array}$ \\
\hline Site of origin & $\begin{array}{l}\text { 'Right neck mass' } \\
\text { (mediastinal into } \\
\text { right supraclavicular } \\
\text { fossa) }\end{array}$ & Abdominal mass & Supraclavicular lymph node & Right inguinal lymph nod \\
\hline MYCN status & Not amplified & Not amplified & Diagnostic biopsy: not amplified & Not amplified \\
\hline $\begin{array}{l}\text { Chromosomal } \\
\text { abnormalities }\end{array}$ & $\begin{array}{l}1 \mathrm{p} \text { loss, } 11 \mathrm{q} \text { and } 17 \mathrm{q} \\
\text { status inconclusive }\end{array}$ & $\begin{array}{l}1 \mathrm{p} \text { loss, } 11 \mathrm{q} \text { loss, } \\
17 \text { gain }\end{array}$ & $\begin{array}{l}\text { Diagnostic biopsy: 1p loss, } \\
11 q \text { loss, } 17 q \text { gain }\end{array}$ & $\begin{array}{l}\text { 11q loss, } 17 q \text { gain, no } \\
1 \mathrm{p} / 1 \mathrm{q} \text { imbalance }\end{array}$ \\
\hline $\begin{array}{l}\text { Histopathology } \\
\text { immunostaining }\end{array}$ & $\mathrm{CD} 56^{+}, \mathrm{NB} 84^{+}$ & $\mathrm{CD} 6^{+}, \mathrm{NB} 84^{+}$ & Diagnostic biopsy: $\mathrm{CD}^{+} 6^{+}, \mathrm{NB}^{+} 4^{+}$ & $\mathrm{CD} 56^{+}, \mathrm{NB} 84^{+}$ \\
\hline
\end{tabular}

quantified by AF647-conjugated Annexin V (cat. no. A23204; Invitrogen; Thermo Fisher Scientific, Inc.) and $2 \mu \mathrm{g} / \mathrm{ml}$ DAPI (cat. no. D9542; Sigma-Aldrich; Merck KGaA, Darmstadt, Germany) staining using flow cytometry.

Primary patient-derived neuroblastoma cell lines were grown as a monolayer in 96-well plates coated with human recombinant laminin 521 (cat. no. LN-521; Biolamina AB, Sundbyberg, Sweden) according to the manufacturer's instructions.

Xenograft cancer models. All experimental procedures were non-retrospectively approved by a the Brunel University London Ethics Committee and the Home Office and were conducted under the Animal Scientific Procedures Act, 1986 (UK). In addition, we confirm that the tumour burden did not exceed the recommended dimensions.

Forty four-week-old female mice (initial weight 20-23 g), immunodeficient NOD/SCID (purchased from Charles River Laboratories, Margate, UK) were injected subcutaneously into the right flank with $5 \times 10^{6}$ neuroblastoma cells in a 1:1 mixture of Matrigel (Corning, Inc., Corning, NY, USA) and phosphate-buffered saline (PBS). After tumours reached the size of $5 \mathrm{~mm}$ in diameter, the mice were randomly assigned to 4 groups (10 mice/group) and PBS, 5x10 $10^{6}$ TRAIL-MSCs labelled with DiR (cat. no. D12731; Thermo Fisher Scientific, Inc.), Bortezomib ( $1 \mathrm{mg} / \mathrm{kg}$ body weight) and their combination were administered intraperitoneally every 3 days for 3 weeks. Fluorescent TRAIL-MSCs were tracked in vivo using the IVIS Lumina Imaging System (Caliper Life Sciences, Hopkinton, MA, USA). Tumour size was monitored with a calliper and calculated according to the formula: $\mathrm{V}=\left(\right.$ length $\mathrm{x}$ width $\left.{ }^{2}\right) / 2$. Mice were housed under a 12-h light/dark cycle in a specific pathogen-free facility with controlled temperature and humidity $\left(20-24^{\circ} \mathrm{C}, 45-65 \%\right.$ humidity) and allowed access to food and water ad libitum. Body weight and general physical status were recorded daily, and the mice were sacrificed by cervical dislocation when the tumour reached $1.2 \mathrm{~cm}$ in diameter.
Flow cytometry of lentivirus-transduced cells. For the expression detection of TRAIL, MSC cells were stained with a phycoerythrin (PE)-conjugated anti-TRAIL antibody (dilution, 1:100; cat. no. 550516; BD Biosciences, Franklin Lakes, NJ, USA) and analysed by flow cytometry.

Statistical analysis. All data are expressed as the means \pm standard deviation (SD). Statistical significance between different test conditions was determined using Student's t-test. Probability values $<0.05$ were considered to indicate a statistically significant result. The statistical analysis of survival was carried out using a log-rank test and the SPSS 16.0 software (SPSS, Inc., Chicago, IL, USA).

\section{Results}

Expression of DR4 and DR5 death receptors in neuroblastoma cells. The presence of death receptors in cancer cells is a valuable biomarker to determine sensitivity to TRAIL. We therefore quantified the expression of DR4 and DR5 in a panel of established (classic) or patient-derived neuroblastoma cells and investigated whether the anticancer drug Bortezomib could be used to enhance the expression of TRAIL receptors.

All classic neuroblastoma cells expressed DR5 receptor while the expression of DR4 was most prominent in a subset of neuroblastoma cell lines. The expression of DR5 was markedly increased after treatment with $20 \mathrm{nM}$ Bortezomib for $24 \mathrm{~h}$ whereas the DR4 receptor was increased by the drug only in the Kelly and SKNAS cell lines (Fig. 1A).

There was a wide difference in expression of death receptors in patient-derived cell lines, ranging from strong to undetectable. In keeping with the results obtained with classic neuroblastoma cell lines, Bortezomib enhanced the expression of DR4-5 also in primary cells (Fig. 1B).

TRAIL-MSCs induce neuroblastoma cell death in vitro. To examine whether the TRAIL-death receptor system could be exploited for therapeutic purposes in neuroblastoma, the 

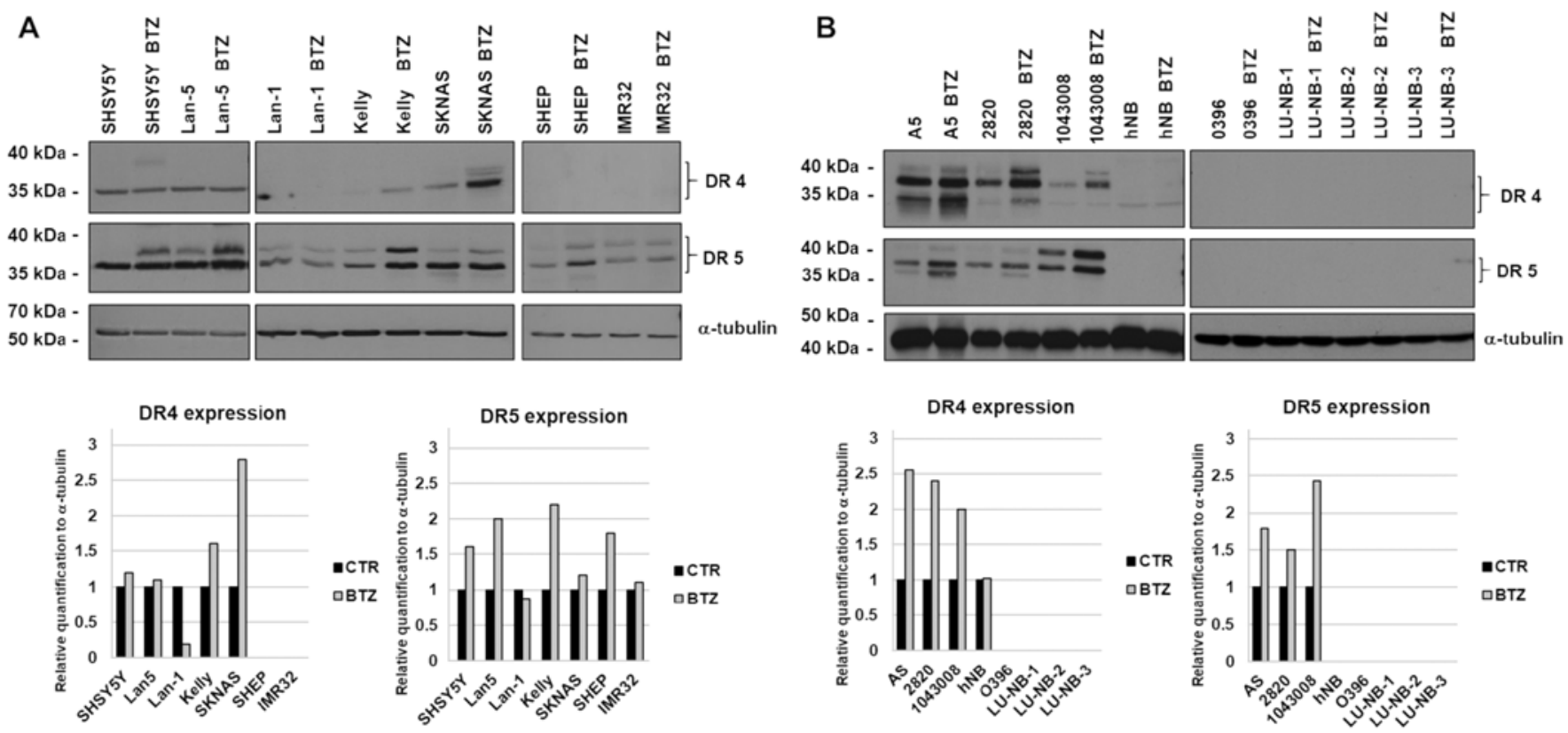

Figure 1. Classic and patient-derived neuroblastoma cell lines exhibit variable expression of TRAIL death receptors. Western blot analysis revealing the expression of DR4 and DR5 in a panel of classic (A) and patient-derived (B) neuroblastoma cell lines in the presence or absence of BTZ. $\alpha$-tubulin was used as a loading control. Quantification of DR4 and DR5 expression relative to control ( $\alpha$-tubulin) is displayed at the bottom of each set of western blots. TRAIL, tumour necrosis factor-related apoptosis-inducing ligand; BTZ, Bortezomib; CTR, control.
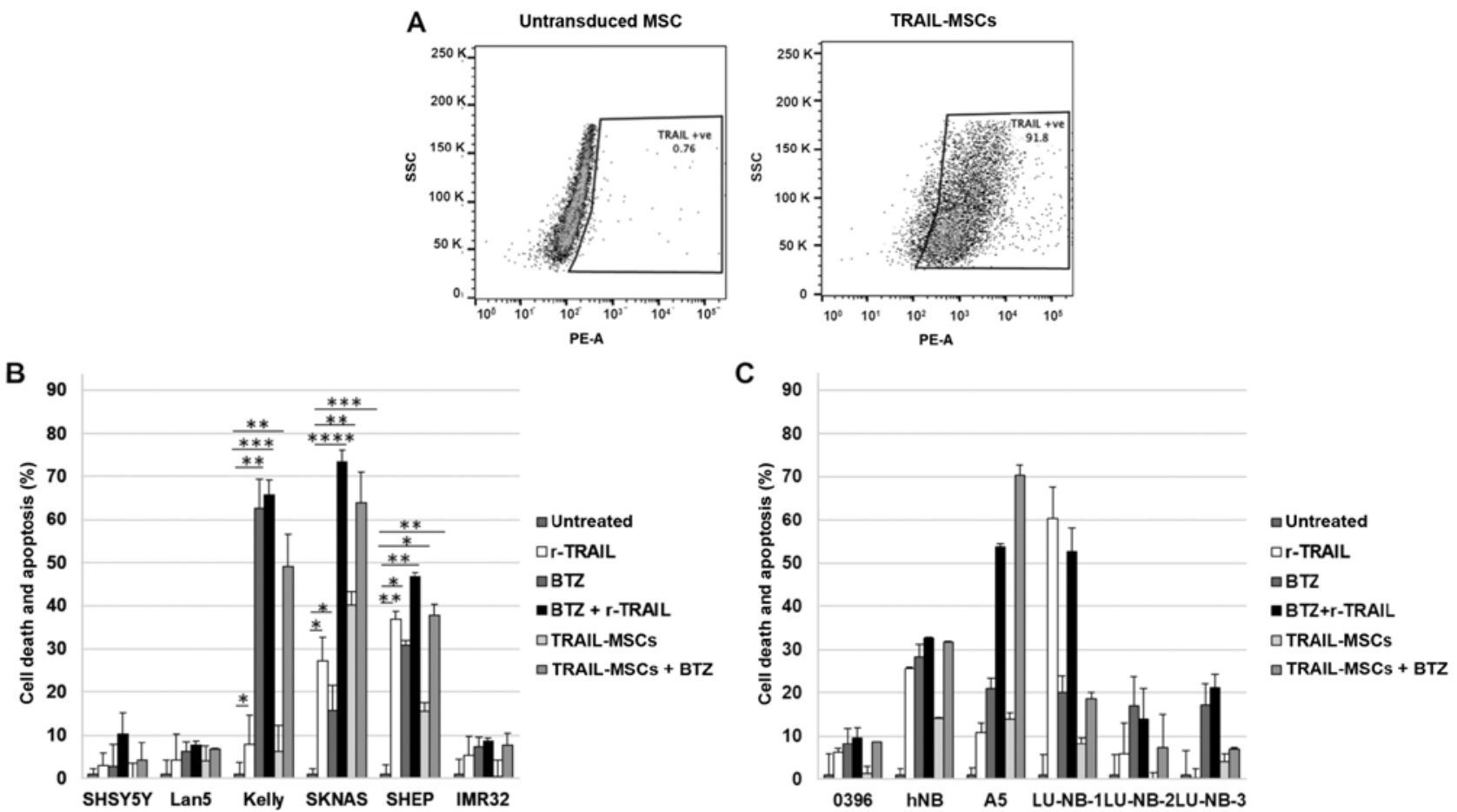

Figure 2. Combination of TRAIL-MSCs with BTZ causes synergistic cell death of classic and patient-derived neuroblastoma cell lines. (A) MSCs infected with a TRAIL lentivirus, or parental cells, were subjected to flow cytometric analysis with a TRAIL antibody. Cell death assays; (B) classic or (C) patient-derived neuroblastoma cell lines were cultured in the presence or absence of recombinant TRAIL (r-TRAIL), BTZ, mesenchymal stem cells engineered to express secreted TRAIL (TRAIL-MSCs) or their combinations. Error bars indicate the standard errors of the means of three (Kelly and SKNAS) or two (primary cell lines) experiments. ${ }^{*} \mathrm{P}<0.05 ;{ }^{* *} \mathrm{P}<0.01 ;{ }^{* * * *} \mathrm{P}<0.001 ;{ }^{* * * * *} \mathrm{P}<0.0001$. MSCs, mesenchymal stem cells; TRAIL, tumour necrosis factor-related apoptosis-inducing ligand; BTZ, Bortezomib.

different cell lines were subjected to in vitro killing assays. Neuroblastoma cells were cultured in the presence of soluble, recombinant TRAIL (r-TRAIL), Bortezomib, TRAIL-MSCs and their combinations. Before performing the experiments,
TRAIL expression on the surface by the modified MSCs was verified by flow cytometry (Fig. 2A). The results revealed that soluble TRAIL and TRAIL-MSCs could induce killing of death receptor-positive cell lines that was increased by 


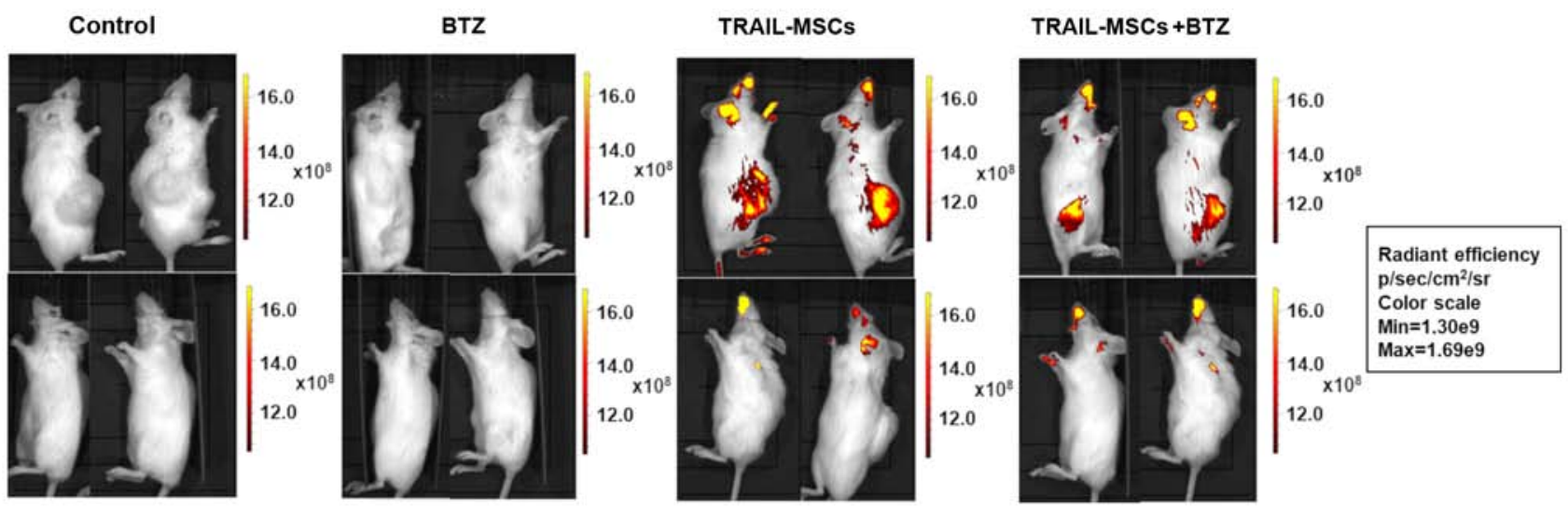

Figure 3. TRAIL-MSCs home into neuroblastoma tumours growing in vivo. TRAIL-MSCs were stained with the vital dye DiR and injected intraperitoneally into mice with tumours growing in the right flank. IVIS Lumina Imaging System (Caliper Life Sciences) confirmed that human TRAIL- MSCs infiltrated subcutaneous neuroblastoma tumour masses. The colour scale indicates the intensity of DiR signal, with the yellow colour indicating the strongest intensity. MSCs, mesenchymal stem cells; TRAIL, tumour necrosis factor-related apoptosis-inducing ligand; BTZ, Bortezomib.

A

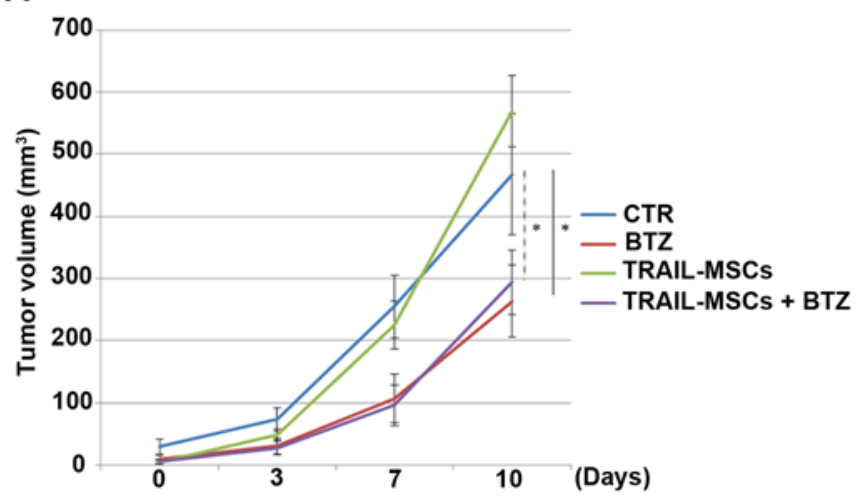

B

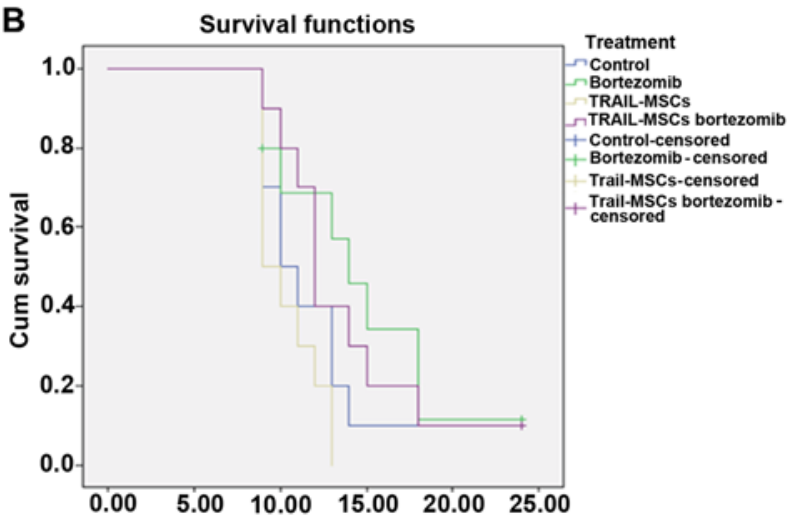

Figure 4. Bortezomib, but not TRAIL-MSCs, treatment slow down the growth of neuroblastoma xenografts. (A) Tumour growth curves. SKNAS cells were injected in the right flanks of mice and treatments were started after tumours reached $\sim 50 \mathrm{~mm}^{3}$. The results are expressed as the tumour volume means $\pm \mathrm{SD}$ $\left(\mathrm{n}=10,{ }^{*} \mathrm{P}=0.05\right)$. (B) Survival curves. Log-rank test indicates that there is no significant effect on mice survival after TRAIL-MSCs or bortezomib treatments $(\mathrm{P}=0.051)$. MSCs, mesenchymal stem cells; TRAIL, tumour necrosis factor-related apoptosis-inducing ligand; BTZ, Bortezomib.

Bortezomib. The classic neuroblastoma cell line SKNAS was particularly sensitive to the combination, with $60-70 \%$ of cells undergoing apoptosis (Fig. 2B). Primary cells were generally less sensitive to soluble TRAIL or TRAIL-MSCs, and, as anticipated, the degree of cell death was in most instances proportional to the expression levels of the TRAIL receptors (Fig. 2C). Intraperitoneally injected TRAIL-MSCs migrate to neuroblastoma xenotransplants. Since TRAIL-MSCs and the combined treatment with Bortezomib enhanced TRAILinduced apoptosis in vitro, we evaluated the therapeutic efficacy of this treatment in vivo. SKNAS were injected subcutaneously into the flank of NOD/SCID mice to establish a xenograft tumour model.

Tumours were allowed to grow until they reached a volume of $50 \mathrm{~mm}^{3}$. Mice were then randomly assigned into 4 groups and treated with vehicle (PBS), TRAIL-MSCs labelled with the fluorescent lipophilic dye DiR, Bortezomib or their combination.

Fluorescent TRAIL-MSCs were tracked in vivo using the IVIS Lumina Imaging System (Caliper Life Sciences). Animals were imaged $24 \mathrm{~h}$ after injection to determine the localisation of TRAIL-MSCs in vivo. A strong signal from DiR-labeled TRAIL-MSCs was detected in the flanks containing the tumour masses whereas a weak signal was detected in other anatomical locations (Fig. 3). Control animals receiving no MSC injections were negative for fluorescence. To evaluate the effect of TRAIL-MSCs in tumour growth, mice were injected with TRAIL-MSCs, Bortezomib or TRAIL-MSCs+Bortezomib every 3 days for 3 weeks and monitored until tumour masses reached a diameter of $1.2 \mathrm{~cm}$ or mice lost $20 \%$ of their weight or showed signs of distress. There were no significant changes in tumour volumes in mice injected with the TRAIL-MSCs compared with the control group, but a significant anticancer effect was noted in the Bortezomib groups (Fig. 4A). We did not observe statistically significant differences in survival between different treatment groups, but there was a trend of increased survival in the Bortezomib-treated mice, consistent with previous observations (32) (Fig. 4B).

\section{Discussion}

Gene rearrangements and mutation of key oncogenes such as MYCN, ALK, ATRX, TERT and chromosomal losses or reduced expression of CLU, CHD5, PHOX2B, CASZ1, 
PML and other tumour suppressor genes are thought to play a crucial role in the pathogenesis of neuroblastoma (35-39). Despite the significant advances in the understanding of its molecular causes, the life expectancy of patients bearing high-risk neuroblastoma is still very poor, suggesting that new therapeutic approaches are urgently needed. MYCN, the main neuroblastoma oncogene, is essentially undruggable (40). Small molecule inhibitors against ALK have been developed, however, monotherapies with small molecule inhibitors are prone to the problem of resistance and new therapies based on the inhibition of molecular drivers, for example by small interfering RNAs or CRISPR, are still far from being translated into clinical practice.

One of the many challenges of developing a therapy based on biomolecules is the delivery of these to the tumour site. It has been recently revealed that MSCs can specifically home in the tumour stroma, and this property can be exploited for cancer therapy. In this context, the death ligand TRAIL was reported to induce apoptosis selectively in tumour cells while sparing normal cells in vitro and in vivo $(41,42)$. Recently, several research groups have explored the possibility of using TRAIL as an anticancer molecule that could be delivered in the tumour microenvironment by mesenchymal stem cells. Loebinger et al demonstrated that TRAIL-MSCs were able to home and kill tumour cells, and significantly induce cancer regression in a lung metastatic cancer model of breast cancer cells (20). In addition, TRAIL-expressing MSCs exhibited anticancer activity in other experimental tumour models, such as glioma and sarcoma (43-45). Despite expressing death receptors, cancer cells can become resistant to TRAILinduced apoptosis $(46,47)$. Several studies have indicated that Bortezomib can reverse resistance of cancer cells to TRAIL killing by increasing the expression of DR4 and DR5 (48). Notably, Naumann et al reported that Bortezomib synergised with TRAIL in inducing apoptosis of neuroblastoma cells (49).

A key question for the potential exploitation of MSCs in neuroblastoma therapeutics is whether stromal cells injected systemically can reach tumour sites. Contradicting information has been published that still leaves the question open. For example, a previous study suggested that neuroblastoma tumours are unable to attract systemically injected MSCs, whereas a recent study revealed imaging of MSCs infiltrating human neuroblastomas growing in vivo $(50,51)$.

To further address this issue, we investigated whether MSCs engineered to express TRAIL were attracted by and able to kill neuroblastoma cells transplanted into immunocompromised mice. Firstly, MSCs expressing TRAIL were co-cultured with classical and patient-derived neuroblastoma cell lines and subjected to cell killing assays. The protease inhibitor and anticancer drug Bortezomib was used to increase the expression of death receptors and sensitise cells to TRAIL killing. Once we had identified the cell line more susceptible to TRAIL-MSCs killing, we carried out xenotransplantation experiments to assess whether the engineered stem cells were attracted by neuroblastomas. Bioluminescent imaging (BLI) clearly indicated that TRAIL-MSCs infiltrated neuroblastomas hours after intraperitoneal injections. Disappointingly, despite the fact that TRAIL-MSCs were able to kill SKNAS cells in vitro, they were not able to do so in vivo and the marginal therapeutic effect that we observed was caused by Bortezomib. Resistance to TRAIL killing may have different causes, including high expression of decoy receptors and downregulation or upregulation of apoptotic proteins. Expression of the intracellular apoptotic inhibitor c-FLIP can confer TRAIL resistance in different types of cancer cell lines and it may be involved in the protection of neuroblastoma cells from the cytotoxic effect of TRAIL (52). Deficient expression of caspases, in particular caspase-8, essential with FADD to form the death receptor complex DISC, may contribute to TRAIL resistance (53). Also, overexpression of $\mathrm{Bcl}-2$ or $\mathrm{Bcl}-\mathrm{x}$ or loss of $\mathrm{Bax}$ and Bad function or high expression of an inhibitor of apoptotic proteins could lead to TRAIL resistance (54). Furthermore, high expression of inhibitors that act downstream of the receptors, which includes XIAP, c-IAP1, c-IAP2 and survivin could block the activation and activity of caspase-9, -3 and -7 (55). It is possible that one of these mechanisms of resistance is activated and selected in tumours developing in vivo and could be responsible for the failure of TRAIL-MSCs to kill their targets. An alternative explanation of the failure of the MSCs to induce cancer regression could be that the cells have lost their ability to express TRAIL in the tumour microenvironment. Although we cannot exclude this possibility, it is unlikely since the same TRAIL-modified MSCs have been previously used to successfully inhibit breast cancer growth in immunodeficient mice $(20,26)$.

Nonetheless, the present study suggests that mesenchymal stem cells are suitable for neuroblastoma cell and gene therapy but should be loaded with biomolecules more effective than TRAIL in further preclinical studies. For example, MSCs producing interferon gamma (IFN $\gamma$ ) have shown promise in reducing neuroblastoma growth when injected intratumorally (56). In light of this study, it is likely that systemic injections of MSCs producing IFN $\gamma$ or other neuroblastoma-specific drugs could be successfully developed for neuroblastoma therapeutics.

\section{Acknowledgements}

Not applicable.

\section{Funding}

The present study was supported by a Niamh's Next Step/SPARKS and Associazione Italiana per la Lotta al Neuroblastoma awards to AS and NIHR GOSH BRC to JA and NS.

\section{Availability of data and materials}

The datasets and cell lines used in the study are available from the corresponding author upon reasonable request.

\section{Authors' contributions}

The study was conceived and written by AS and VN. VN performed all the experiments with the assistance of RP and KK. SMJ, JB, JA and DB provided the patient-derived materials, the cell lines and the key reagents, and were involved in the data analysis and the interpretation of the results. NS 
carried out the pathology analyses. EK assisted with the interpretation, revision and analysis of the data. All authors read and approved the manuscript and agree to be accountable for all aspects of the research in ensuring that the accuracy or integrity of any part of the work are appropriately investigated and resolved.

\section{Ethics approval and consent to participate}

Consent for the isolation of cell lines from patient material was obtained in accordance with the Great Ormond Street Hospital (London, UK) Ethics Committee regulations. All experimental procedures were non-retrospectively approved by the Brunel University London Ethics Committee and the Home Office and were conducted under the Animal Scientific Procedures Act, 1986 (UK).

\section{Patient consent for publication}

Not applicable.

\section{Competing interests}

The authors declare that they have no competing interests.

\section{References}

1. Matthay KK, Maris JM, Schleiermacher G, Nakagawara A Mackall CL, Diller L and Weiss WA: Neuroblastoma. Nat Rev Dis Primers 2: 16078, 2016.

2. Yang RK and Sondel PM: Anti-GD2 strategy in the treatment of neuroblastoma. Drugs Future 35: 665, 2010.

3. Maris JM: Recent advances in neuroblastoma. N Engl J Med 362 2202-2211, 2010.

4. Fish JD and Grupp SA: Stem cell transplantation for neuroblastoma. Bone Marrow Transplant 41: 159-165, 2008.

5. Wagner LM and Danks MK: New therapeutic targets for the treatment of high-risk neuroblastoma. J Cell Biochem 107: 46-57, 2009.

6. Ren N, Atyah M, Chen WY and Zhou CH: The various aspects of genetic and epigenetic toxicology: Testing methods and clinical applications. J Transl Med 15: 110, 2017.

7. Bianco P, Robey PG and Simmons PJ: Mesenchymal stem cells: Revisiting history, concepts, and assays. Cell Stem Cell 2: 313-319, 2008

8. Hwang NS, Zhang C, Hwang YS and Varghese S: Mesenchymal stem cell differentiation and roles in regenerative medicine. Wiley Interdiscip Rev Syst Biol Med 1: 97-106, 2009.

9. Pittenger MF, Mackay AM, Beck SC, Jaiswal RK, Douglas R, Mosca JD, Moorman MA, Simonetti DW, Craig S and Marshak DR: Multilineage potential of adult human mesenchymal stem cells. Science 284: 143-147, 1999.

10. Granero-Molto F, Weis JA, Longobardi L and Spagnoli A: Role of mesenchymal stem cells in regenerative medicine: Application to bone and cartilage repair. Expert Opin Biol Ther 8: 255-268, 2008.

11. Savkovic V, Li H, Seon JK, Hacker M, Franz S and Simon JC: Mesenchymal stem cells in cartilage regeneration. Curr Stem Cell Res Ther 9: 469-488, 2014.

12. Dezawa M, Ishikawa H, Itokazu Y, Yoshihara T, Hoshino M, Takeda S, Ide C and Nabeshima Y: Bone marrow stromal cells generate muscle cells and repair muscle degeneration. Science 309: 314-317, 2005.

13. Nakamizo A, Marini F, Amano T, Khan A, Studeny M, Gumin J, Chen J, Hentschel S, Vecil G, Dembinski J, et al: Human bone marrow-derived mesenchymal stem cells in the treatment of gliomas. Cancer Res 65: 3307-3318, 2005.

14. Duan X, Guan H, Cao Y and Kleinerman ES: Murine bone marrow-derived mesenchymal stem cells as vehicles for interleukin-12 gene delivery into Ewing sarcoma tumors. Cancer 115: $13-22,2009$
15. Studeny M, Marini FC, Champlin RE, Zompetta C, Fidler IJ and Andreeff M: Bone marrow-derived mesenchymal stem cells as vehicles for interferon-beta delivery into tumors. Cancer Res 62: 3603-3608, 2002.

16. Ozawa K, Sato K, Oh I, Ozaki K, Uchibori R, Obara Y, Kikuchi Y, Ito T, Okada T, Urabe M, et al: Cell and gene therapy using mesenchymal stem cells (MSCs). J Autoimmun 30: 121-127, 2008.

17. 1Javazon EH, Beggs KJ and Flake AW: Mesenchymal stem cells: Paradoxes of passaging. Exp Hematol 32: 414-425, 2004.

18. Xin H, Kanehira M, Mizuguchi H, Hayakawa T, Kikuchi T, Nukiwa T and Saijo Y: Targeted delivery of CX3CL1 to multiple lung tumors by mesenchymal stem cells. Stem Cells 25: 1618-1626, 2007.

19. Loebinger MR and Janes SM: Stem cells as vectors for antitumour therapy. Thorax 65: 362-369, 2010.

20. Loebinger MR, Eddaoudi A, Davies D and Janes SM: Mesenchymal stem cell delivery of TRAIL can eliminate metastatic cancer. Cancer Res 69: 4134-4142, 2009.

21. Pitti RM, Marsters SA, Ruppert S, Donahue CJ, Moore A and Ashkenazi A: Induction of apoptosis by Apo-2 ligand, a new member of the tumor necrosis factor cytokine family. J Biol Chem 271: 12687-12690, 1996.

22. Kelley SK and Ashkenazi A: Targeting death receptors in cancer with Apo2L/TRAIL. Curr Opin Pharmacol 4: 333-339, 2004

23. Wiley SR, Schooley K, Smolak PJ, Din WS, Huang CP, Nicholl JK, Sutherland GR, Smith TD, Rauch C, Smith CA, et al: Identification and characterization of a new member of the TNF family that induces apoptosis. Immunity 3: 673-682, 1995.

24. Herbst RS, Eckhardt SG, Kurzrock R, Ebbinghaus S, O'D wyer PJ, Gordon MS, Novotny W, Goldwasser MA, Tohnya TM, Lum BL, et al: Phase I dose-escalation study of recombinant human Apo2L/TRAIL, a dual proapoptotic receptor agonist, in patients with advanced cancer. J Clin Oncol 28: 2839-2846, 2010.

25. Soria JC, Smit E, Khayat D, Besse B, Yang X, Hsu CP, Reese D, Wiezorek J and Blackhall F: Phase 1b study of dulanermin (recombinant human Apo2L/TRAIL) in combination with paclitaxel, carboplatin, and bevacizumab in patients with advanced nonsquamous non-small-cell lung cancer. J Clin Oncol 28: 1527-1533, 2010.

26. Yuan Z, Kolluri KK, Sage EK, Gowers KH and Janes SM: Mesenchymal stromal cell delivery of full-length tumor necrosis factor-related apoptosis-inducing ligand is superior to soluble type for cancer therapy. Cytotherapy 17: 885-896, 2015.

27. Sheard MA, Asgharzadeh S, Liu Y, Lin TY, Wu HW, Ji L, Groshen S, Lee DA and Seeger RC: Membrane-bound TRAIL supplements natural killer cell cytotoxicity against neuroblastoma cells. J Immunother 36: 319-329, 2013.

28. Mueller LP, Luetzkendorf J, Widder M, Nerger K, Caysa H and Mueller T: TRAIL-transduced multipotent mesenchymal stromal cells (TRAIL-MSC) overcome TRAIL resistance in selected CRC cell lines in vitro and in vivo. Cancer Gene Ther 18: 229-239, 2011.

29. Sage EK, Kolluri KK, McNulty K, Lourenco Sda S, Kalber TL, Ordidge KL, Davies D, Gary Lee YC, Giangreco A and Janes SM: Systemic but not topical TRAIL-expressing mesenchymal stem cells reduce tumour growth in malignant mesothelioma. Thorax 69: 638-647, 2014.

30. Loi M, Becherini P, Emionite L, Giacomini A, Cossu I, Destefanis E, Brignole C, Di Paolo D, Piaggio F, Perri P, et al: sTRAIL coupled to liposomes improves its pharmacokinetic profile and overcomes neuroblastoma tumour resistance in combination with Bortezomib. J Control Release 192: 157-166, 2014.

31. Tong HX, Lu CW, Wang QS and Ma LY: Combination of IFNgamma and chemotherapeutic agents increase TRAIL sensitivity of neuroblastoma cell lines. Eur J Pediatr Surg 21: 304-309, 2011.

32. Brignole C, Marimpietri D, Pastorino F, Nico B, Di Paolo D, Cioni M, Piccardi F, Cilli M, Pezzolo A, Corrias MV, et al: Effect of bortezomib on human neuroblastoma cell growth, apoptosis, and angiogenesis. J Natl Cancer Inst 98: 1142-1157, 2006.

33. Braekeveldt N, Wigerup C, Gisselsson D, Mohlin S, Merselius M, Beckman S, Jonson T, Börjesson A, Backman T, Tadeo I, et al: Neuroblastoma patient-derived orthotopic xenografts retain metastatic patterns and geno- and phenotypes of patient tumours. Int J Cancer 136: E252-E261, 2015.

34. Chaiwatanasirikul KA and Sala A: The tumour-suppressive function of CLU is explained by its localisation and interaction with HSP60. Cell Death Dis 2: e219, 2011.

35. Fujita T, Igarashi J, Okawa ER, Gotoh T, Manne J, Kolla V, Kim J, Zhao H, Pawel BR, London WB, et al: CHD5, a tumor suppressor gene deleted from $1 \mathrm{p} 36.31$ in neuroblastomas. J Natl Cancer Inst 100: 940-949, 2008. 
36. Wang C, Liu Z, Woo CW, Li Z, Wang L, Wei JS, Marquez VE, Bates SE, Jin Q, Khan J, et al: EZH2 Mediates epigenetic silencing of neuroblastoma suppressor genes CASZ1, CLU, RUNX3, and NGFR. Cancer Res 72: 315-324, 2012.

37. Corvetta D, Chayka O, Gherardi S, D'Acunto CW, Cantilena S, Valli E, Piotrowska I, Perini G and Sala A: Physical interaction between MYCN oncogene and polycomb repressive complex 2 (PRC2) in neuroblastoma: Functional and therapeutic implications. J Biol Chem 288: 8332-8341, 2013.

38. Dvorkina M, Nieddu V, Chakelam S, Pezzolo A, Cantilena S, Leite AP, Chayka O, Regad T, Pistorio A, Sementa AR, et al: A promyelocytic leukemia protein-thrombospondin-2 axis and the risk of relapse in neuroblastoma. Clin Cancer Res 22: 3398-3409, 2016.

39. Valentijn LJ, Koster J, Zwijnenburg DA, Hasselt NE, van Sluis P, Volckmann R, van Noesel MM, George RE, Tytgat GA, Molenaar JJ, et al: TERT rearrangements are frequent in neuroblastoma and identify aggressive tumors. Nat Genet 47: 1411-1414, 2015.

40. Shalaby T and Grotzer MA: MYC as therapeutic target for embryonal tumors: Potential and challenges. Curr Cancer Drug Targets 16: 2-21, 2016.

41. Walczak H, Miller RE, Ariail K, Gliniak B, Griffith TS, Kubin M, Chin W, Jones J, Woodward A, Le T, et al: Tumoricidal activity of tumor necrosis factor-related apoptosis-inducing ligand in vivo. Nat Med 5: 157-163, 1999.

42. Ashkenazi A, Pai RC, Fong S, Leung S, Lawrence DA, Marsters SA, Blackie C, Chang L, McMurtrey AE, Hebert A, et al: Safety and antitumor activity of recombinant soluble Apo2 ligand. J Clin Invest 104: 155-162, 1999.

43. Mohr A, Lyons M, Deedigan L, Harte T, Shaw G, Howard L, Barry F, O'Brien T and Zwacka R: Mesenchymal stem cells expressing TRAIL lead to tumour growth inhibition in an experimental lung cancer model. J Cell Mol Med 12: 2628-2643, 2008.

44. Menon LG, Kelly K, Yang HW, Kim SK, Black PM and Carroll RS: Human bone marrow-derived mesenchymal stromal cells expressing S-TRAIL as a cellular delivery vehicle for human glioma therapy. Stem Cells 27: 2320-2330, 2009.

45. Grisendi G, Spano C, D'souza N, Rasini V, Veronesi E, Prapa M, Petrachi T, Piccinno S, Rossignoli F, Burns JS, et al: Mesenchymal progenitors expressing TRAIL induce apoptosis in sarcomas. Stem Cells 33: 859-869, 2015.

46. Dyer MJ, MacFarlane M and Cohen GM: Barriers to effective TRAIL-targeted therapy of malignancy. J Clin Oncol 25: 4505-4506, 2007.
47. Rieger J, Frank B, Weller M and Wick W: Mechanisms of resistance of human glioma cells to Apo2 ligand/TNF-related apoptosis-inducing ligand. Cell Physiol Biochem 20: 23-34, 2007.

48. Mahalingam D, Szegezdi E, Keane M, de Jong S and Samali A: TRAIL receptor signalling and modulation: Are we on the right TRAIL? Cancer Treat Rev 35: 280-288, 2009.

49. Naumann I, Kappler R, von Schweinitz D, Debatin KM and Fulda S: Bortezomib primes neuroblastoma cells for TRAIL-induced apoptosis by linking the death receptor to the mitochondrial pathway. Clin Cancer Res 17: 3204-3218, 2011.

50. Bianchi G, Morandi F, Cilli M, Daga A, Bocelli-Tyndall C, Gambini C, Pistoia V and Raffaghello L: Close interactions between mesenchymal stem cells and neuroblastoma cell lines lead to tumor growth inhibition. PLoS One 7: e48654, 2012.

51. Cussó L, Mirones I, Peña-Zalbidea S, García-Vázquez V, GarcíaCastro J and Desco M: Combination of single-photon emission computed tomography and magnetic resonance imaging to track 111in-oxine-labeled human mesenchymal stem cells in neuroblastoma-bearing mice. Mol Imaging 13: 13, 2014.

52. French R, Hayward O, Jones S, Yang W and Clarkson R: Cytoplasmic levels of cFLIP determine a broad susceptibility of breast cancer stem/progenitor-like cells to TRAIL. Mol Cancer 14: 209, 2015.

53. Schneider P, Thome M, Burns K, Bodmer JL, Hofmann K, Kataoka T, Holler N and Tschopp J: TRAIL receptors 1 (DR4) and 2 (DR5) signal FADD-dependent apoptosis and activate NF-kappaB. Immunity 7: 831-836, 1997.

54. LeBlanc H, Lawrence D, Varfolomeev E, Totpal K, Morlan J, Schow P, Fong S, Schwall R, Sinicropi D and Ashkenazi A: Tumor-cell resistance to death receptor - induced apoptosis through mutational inactivation of the proapoptotic Bcl-2 homolog Bax. Nat Med 8: 274-281, 2002.

55. Deveraux QL, Takahashi R, Salvesen GS and Reed JC: X-linked IAP is a direct inhibitor of cell-death proteases. Nature 388: 300-304, 1997.

56. Relation T, Yi T, Guess AJ, La Perle K, Otsuru S, Hasgur S, Dominici M, Breuer $\mathrm{C}$ and Horwitz EM: Intratumoral delivery of interferon $\gamma$-secreting mesenchymal stromal cells repolarizes tumor-associated macrophages and suppresses neuroblastoma proliferation in vivo. Stem Cells 36: 915-924, 2018.

This work is licensed under a Creative Commons Attribution-NonCommercial-NoDerivatives 4.0 International (CC BY-NC-ND 4.0) License. 